\title{
LA-UR-19-21160
}

Approved for public release; distribution is unlimited.

Title:

Author(s): Goff, Ronald Shane

Intended for: Report

Issued:

\section{SQUASHFS RESULTS}

Report

2019-02-13 
Disclaimer:

Los Alamos National Laboratory, an affirmative action/equal opportunity employer, is operated by Triad National Security, LLC for the National Nuclear Security Administration of U.S. Department of Energy under contract 89233218CNA000001. By approving this article, the publisher recognizes that the U.S. Government retains nonexclusive, royalty-free license to publish or reproduce the published form of this contribution, or to allow others to do so, for U.S. Government purposes. Los Alamos National Laboratory requests that the publisher identify this article as work performed under the auspices of the U.S. Department of Energy. Los Alamos National Laboratory strongly supports academic freedom and a researcher's right to publish; as an institution, however, the Laboratory does not endorse the viewpoint of a publication or guarantee its technical correctness. 


\section{SQUASHFS RESULTS}

DOING THINGS FOR SCIENCE 


\section{DEFAULT EVERYTHING}

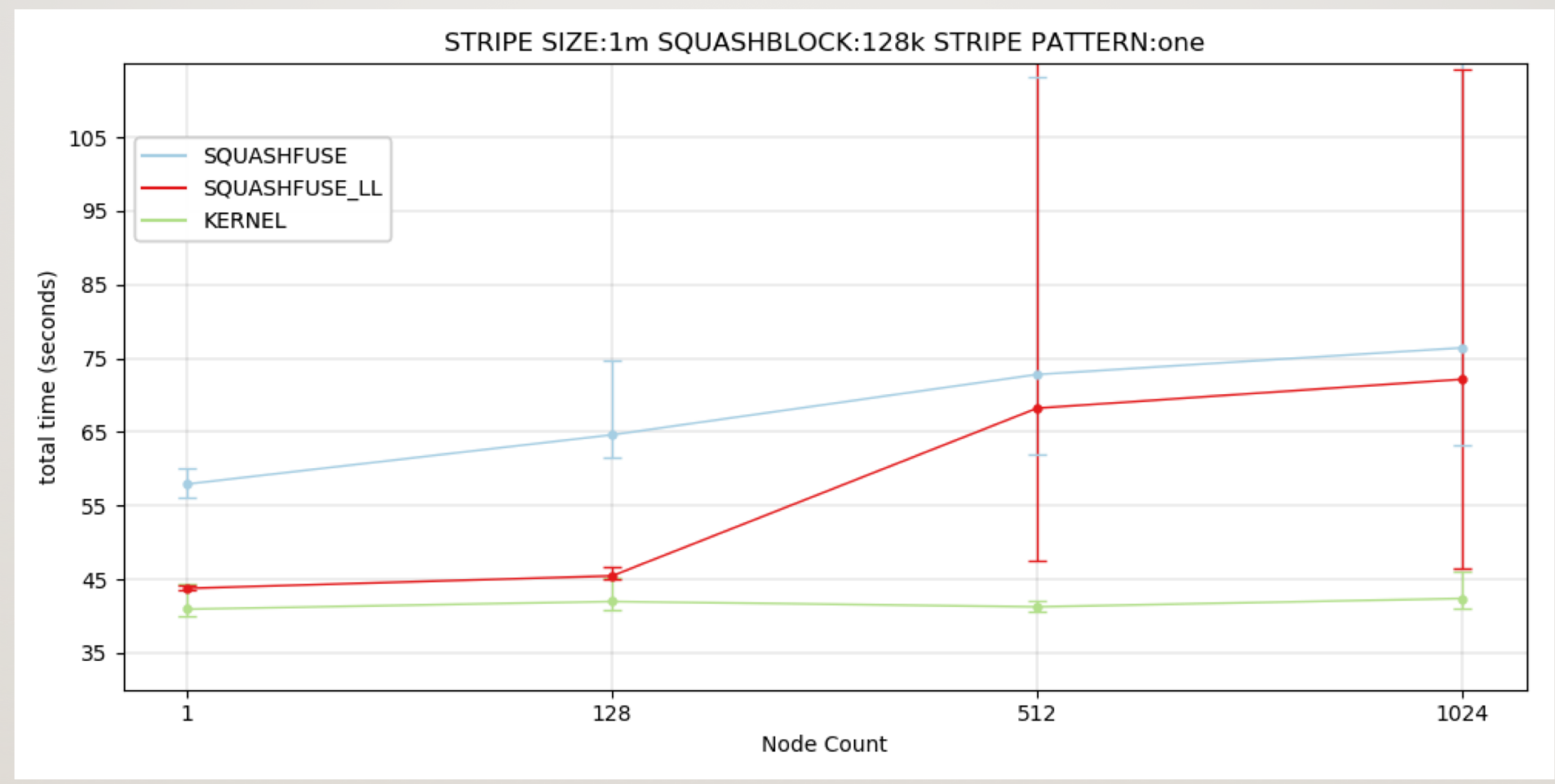




\section{OPTIMIZED STRIPING}

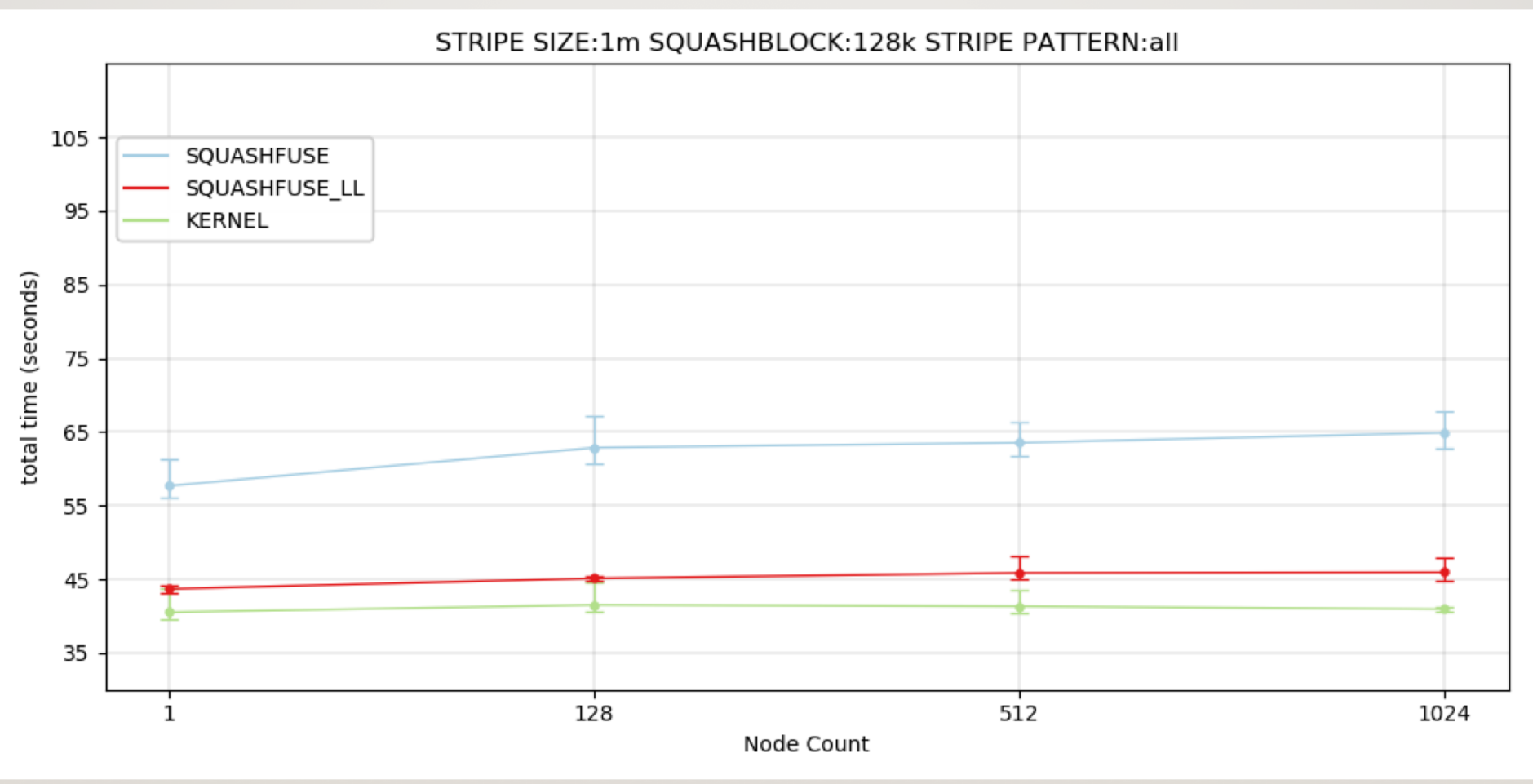




\section{IN MEMORY EXECUTION FOR PYNAMIC}

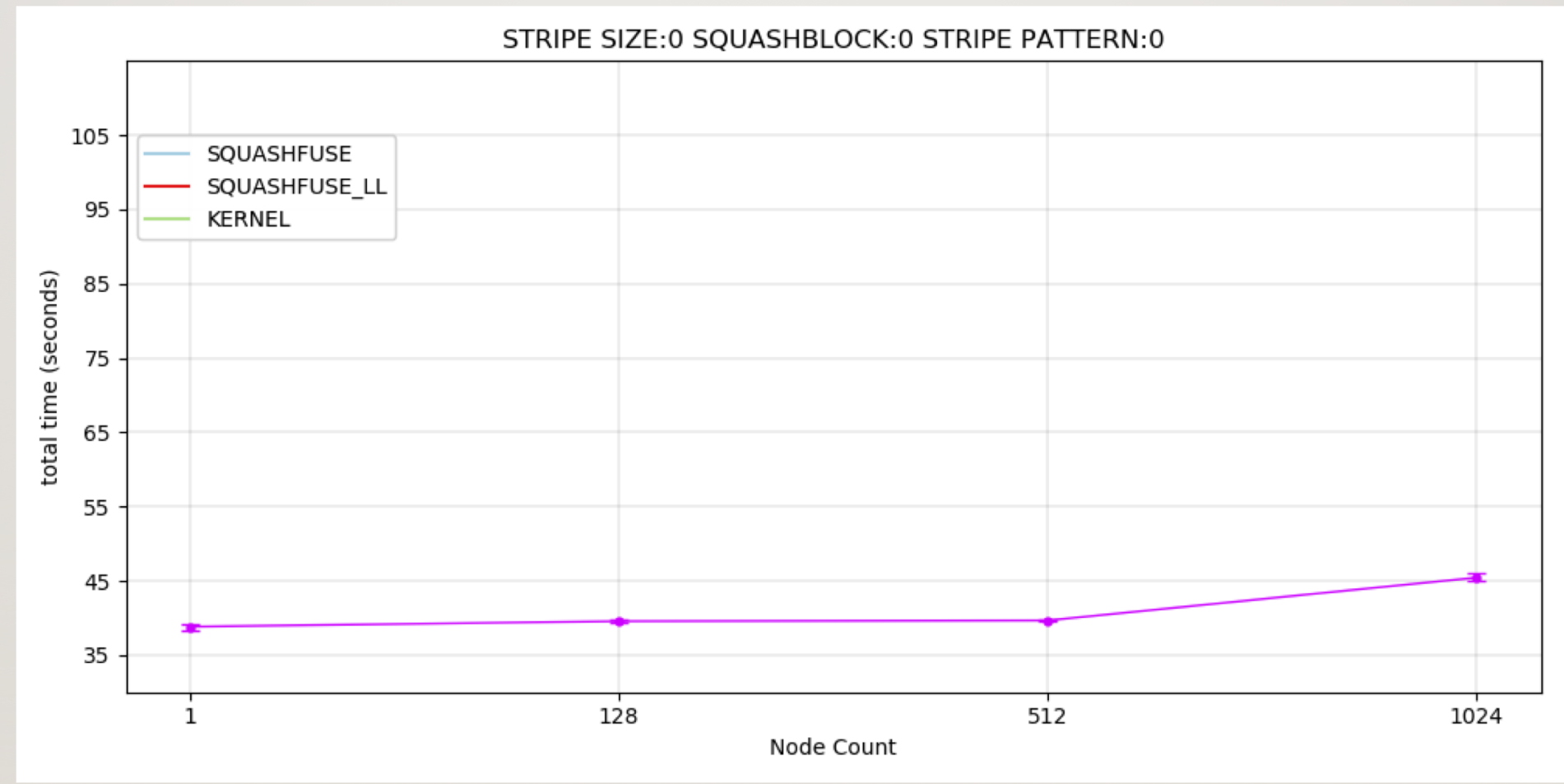




\section{OPTMIZING STRIPE SIZE}

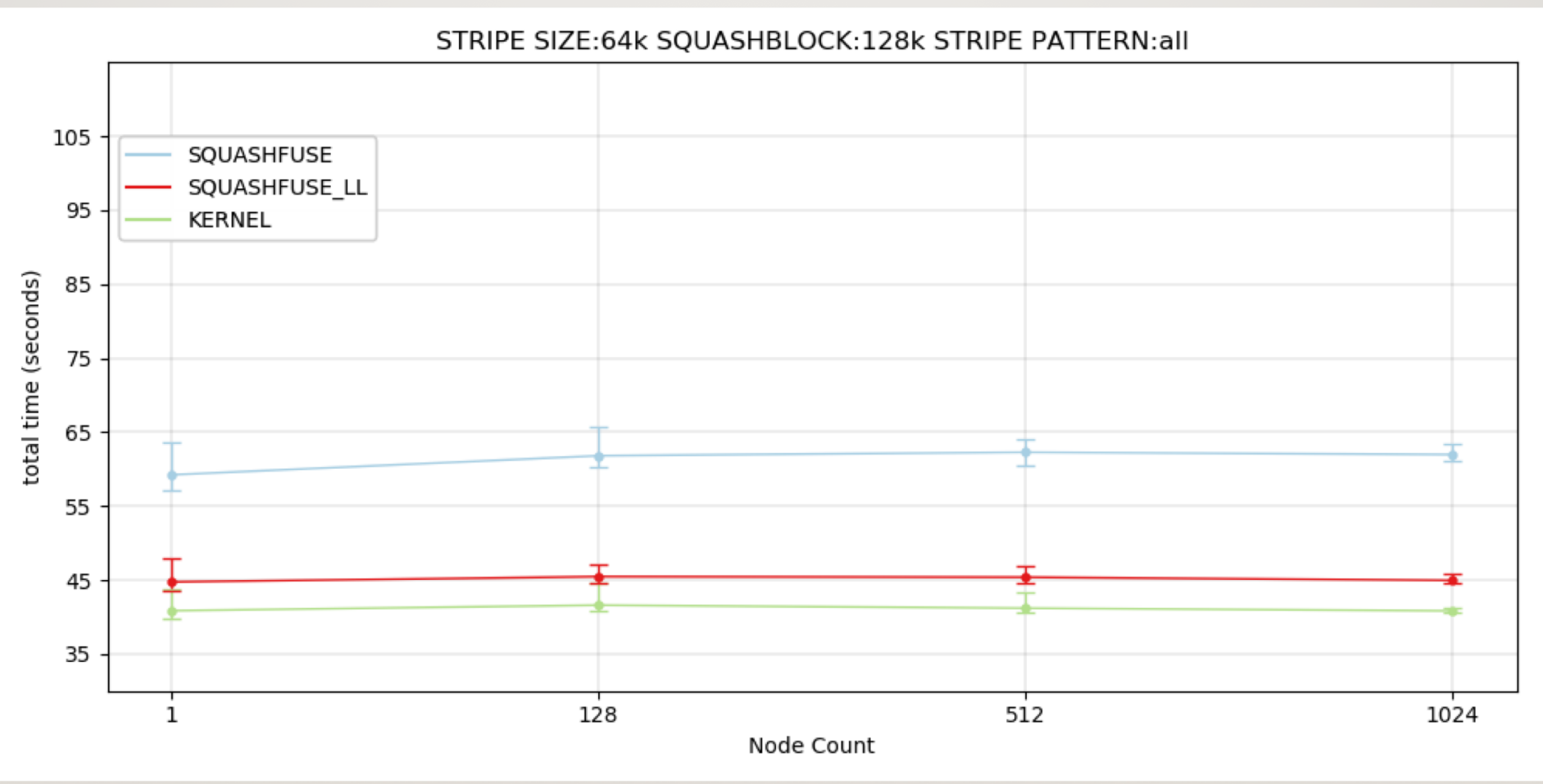




\section{OTHER CONFIGURATIONG}

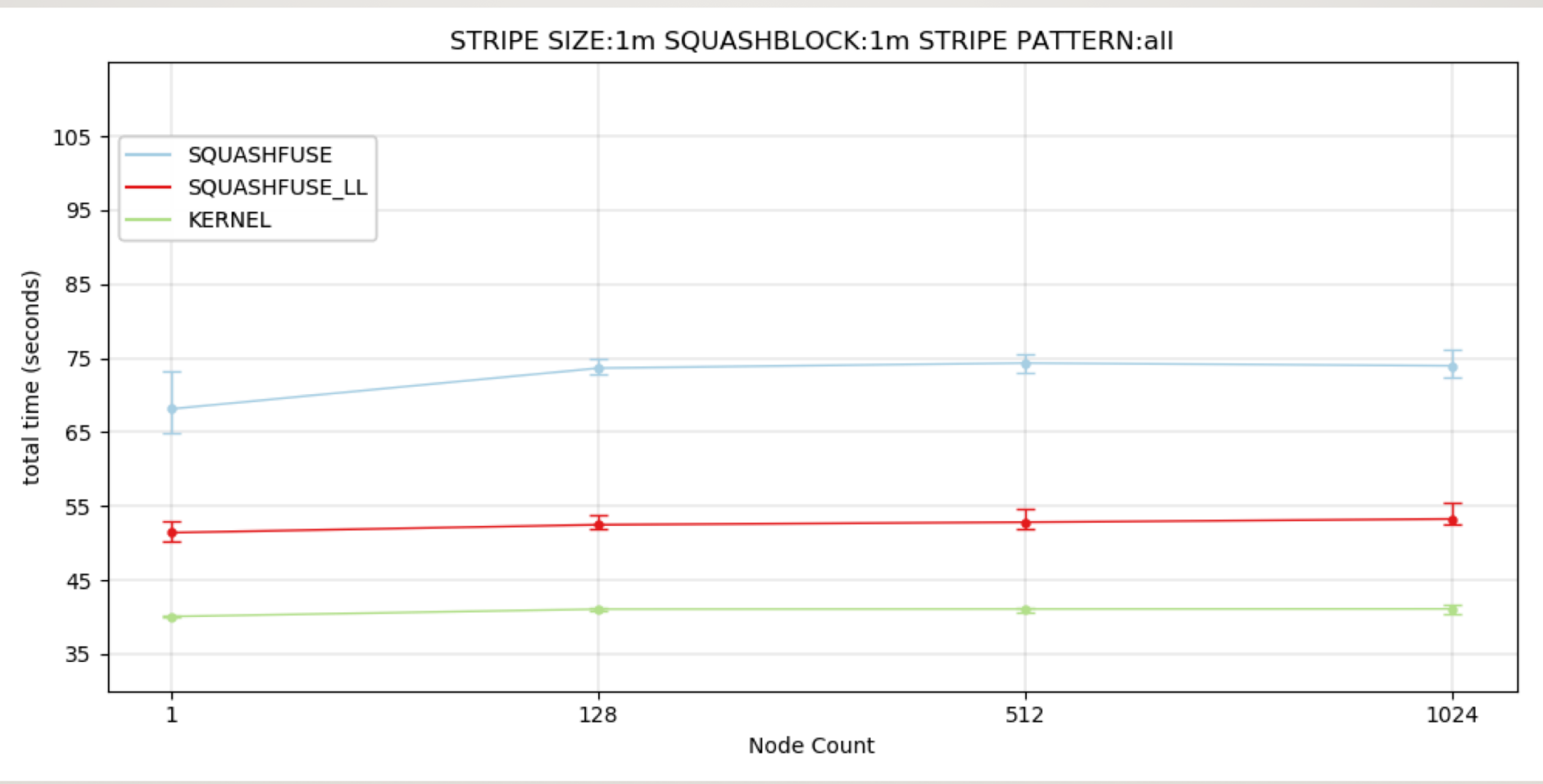




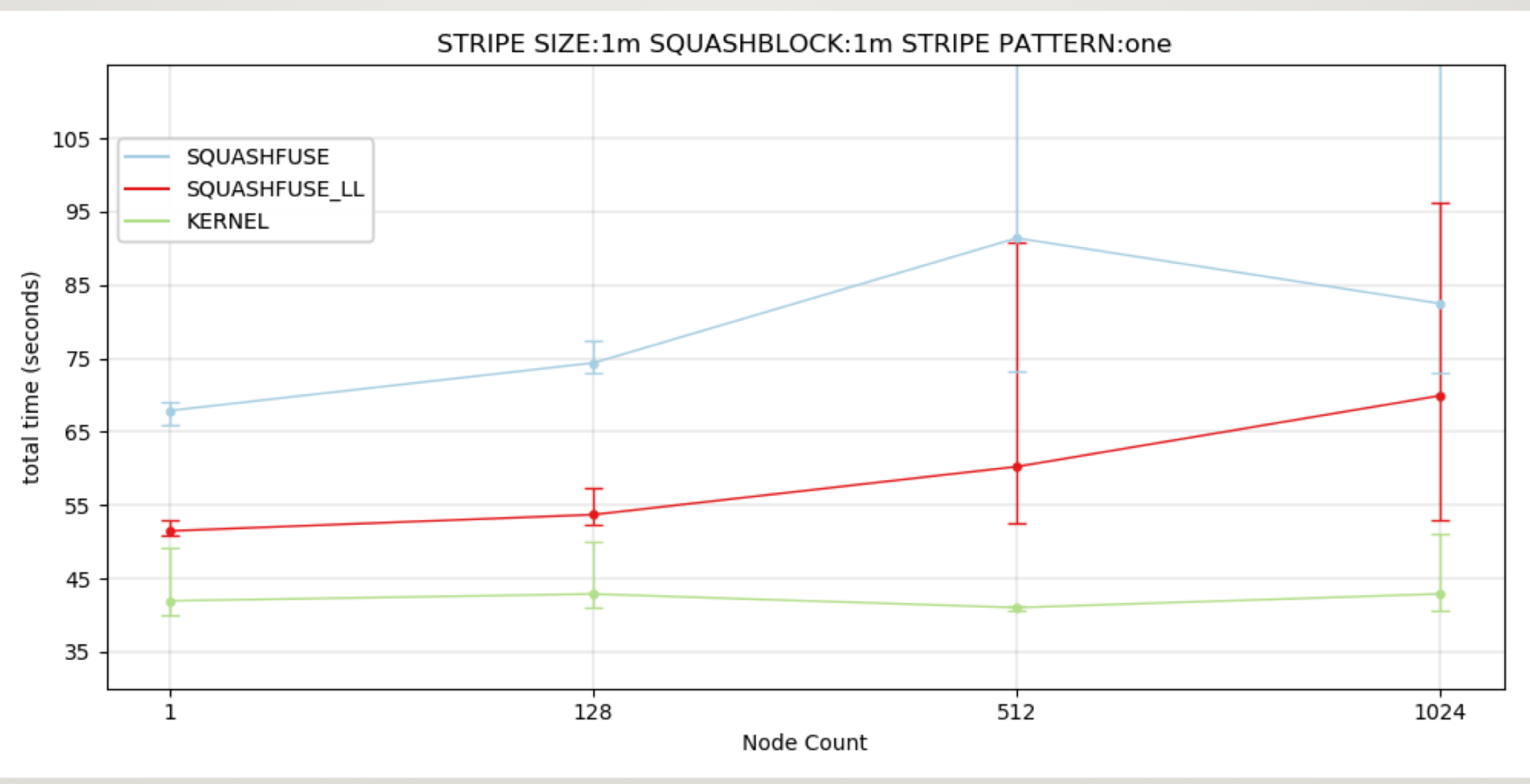




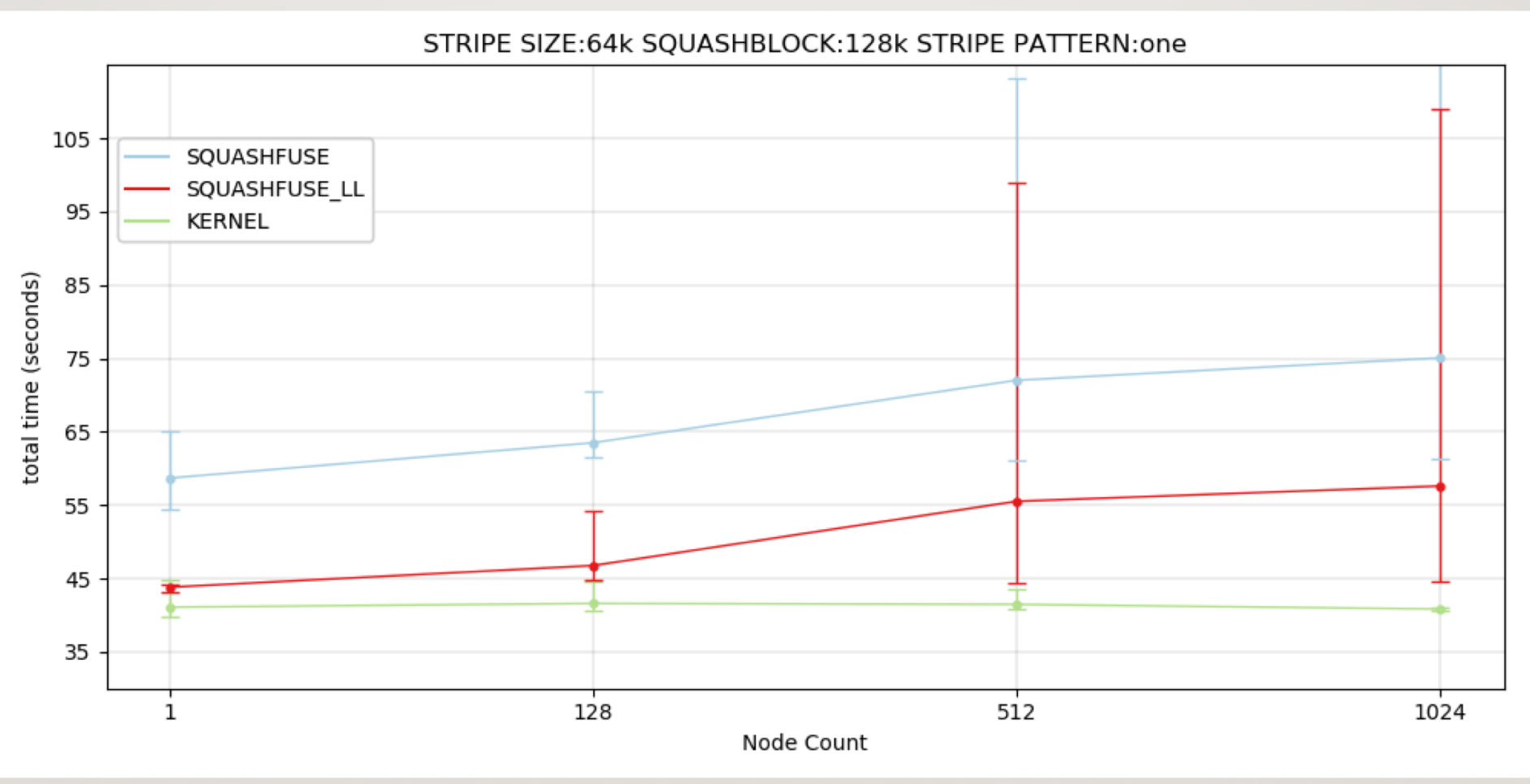

